\title{
Recurrent Hemobilia Due to Right Hepatic Artery Pseudoaneurysm
}

\author{
Mahir Gachabayov, MD, PhD; Kubach Kubachev, MD, PhD; Sergey Mityushin, MD, and \\ Nonna Zarkua, MD, PhD
}

\begin{abstract}
Hemobilia is a potentially life-threatening clinical issue, the etiology of which iatrogenesis is playing increasingly more prominent role. Nowadays the most frequent etiology of hemobilia has shifted toward iatrogenesis owing to increasingly more frequent performance of liver procedures, either open or minimally invasive. Here we report a rare case of recurrent hemobilia after transarterial embolization. A man, aged 57 years, presented with Quincke's triad after cholecystectomy. Computed tomography imaging revealed a pseudoaneurysm of the right hepatic artery. Transarterial embolization failed, and hemobilia recurred. The patient underwent open ligation of the right hepatic artery. Transarterial embolization is a definitive treatment of hemobilia due to vascular issues. The choice of embolizing agent is crucial in transarterial embolization.
\end{abstract}

Keywords: Hemobilia; Hepatic artery; Cholecystectomy; Gastrointestinal hemorrhage; Therapeutic embolization; Ligation

$\mathrm{H}$ emobilia is defined as bleeding into the biliary tract from a fistula between the splanchnic vasculature and any biliary duct. ${ }^{1}$ Francis Glisson first described hemobilia in 1654 in a young nobleman who was stabbed in the right hypochondrium and died following massive upper gastrointestinal bleeding which appeared to originate from a deep laceration of the liver at postmortem examination. ${ }^{2}$ The term "hemobilia" was coined and recognized as a clinical entity by Sandblom in 1948. ${ }^{2-4}$ Hemobilia occurs in a variety of settings including trauma, iatrogenesis, inflammation, oncologic and vascular issues. In the past the most common etiology of hemobilia was liver trauma which encouraged surgeons to name this clinical entity "traumatic hemobilia.", 5 Nowadays, however, the most frequent etiology of hemobilia has shifted toward iatrogenesis owing to increasingly more frequent performance of liver procedures, either open or minimally invasive. ${ }^{6,7}$ Here we report a rare case of recurrent hemobilia after transarterial embolization.

\section{Case Presentation}

A man, aged 57 years, was admitted to Vladimir City Clinical Hospital of Emergency Medicine with a 3-day history of acute cholecystitis and underwent minimal access cholecystectomy. Postoperatively, the patient had minor bilious discharge through the draining tube which resolved in 2 days. The patient was discharged without any other complications on the 7th postoperative day with hemoglobin $14.8 \mathrm{mg} / \mathrm{dL}$ and total bilirubin $2.1 \mathrm{mg} / \mathrm{dL}$. On the 15th postoperative day, the patient presented to the emergency room with a 10-hour history of melena, fatigue, abdominal pain and jaundice. On admission, the patient was pale and subicteric, hypotonic, and normothermic; with blood pressure $100 / 70 \mathrm{~mm} \mathrm{Hg}$, heart rate 104 beats per minute, hemoglobin $9.2 \mathrm{mg} / \mathrm{dL}$, total bilirubin $3.4 \mathrm{mg} / \mathrm{dL}$, and direct bilirubin 2.2 $\mathrm{mg} / \mathrm{dL}$. Esophagogastroduodenoscopy was negative. Ultrasonography revealed dilated common bile duct. To rule out hemobilia (Quincke's triad was present), contrast-enhanced computed tomography imaging was performed which revealed the pseudoaneurysm of the right hepatic artery with the largest diameter of $0.9 \mathrm{~cm}$ (Figure 1). Transarterial embolization of the right hepatic artery using polyvinyl alcohol particles was performed. Melena and abdominal pain resolved. However, on the 6th day following the transarterial embolization of the right hepatic artery, abdominal pain recurred and, on the 7th postoperative day, melena recurred. Contrast-enhanced computed tomography imaging revealed the recurrence of the pseudoaneurysm of the right hepatic artery which enlarged in size (largest diameter- $2.2 \mathrm{~cm}$ ) and partial embolic obstruction of the gastroduodenal artery (Figure 2). The patient underwent urgent laparotomy and ligation of the right hepatic artery. Postoperative course was uneventful. The patient was discharged on 12th postoperative day with hemoglobin 12.5
Corresponding Author: Gachabayov Mahir, MD, PhD; Attending surgeon, Vladimir City Clinical Hospital of Emergency Medicine, Department of Abdominal Surgery, 600022, Stavrovskaya street, 6-73, Vladimir/Russia, Tel: +7(9I5)790I632
Received: June 29, 2017

Revised: October 18, 2017

Accepted: October 31, 2017 

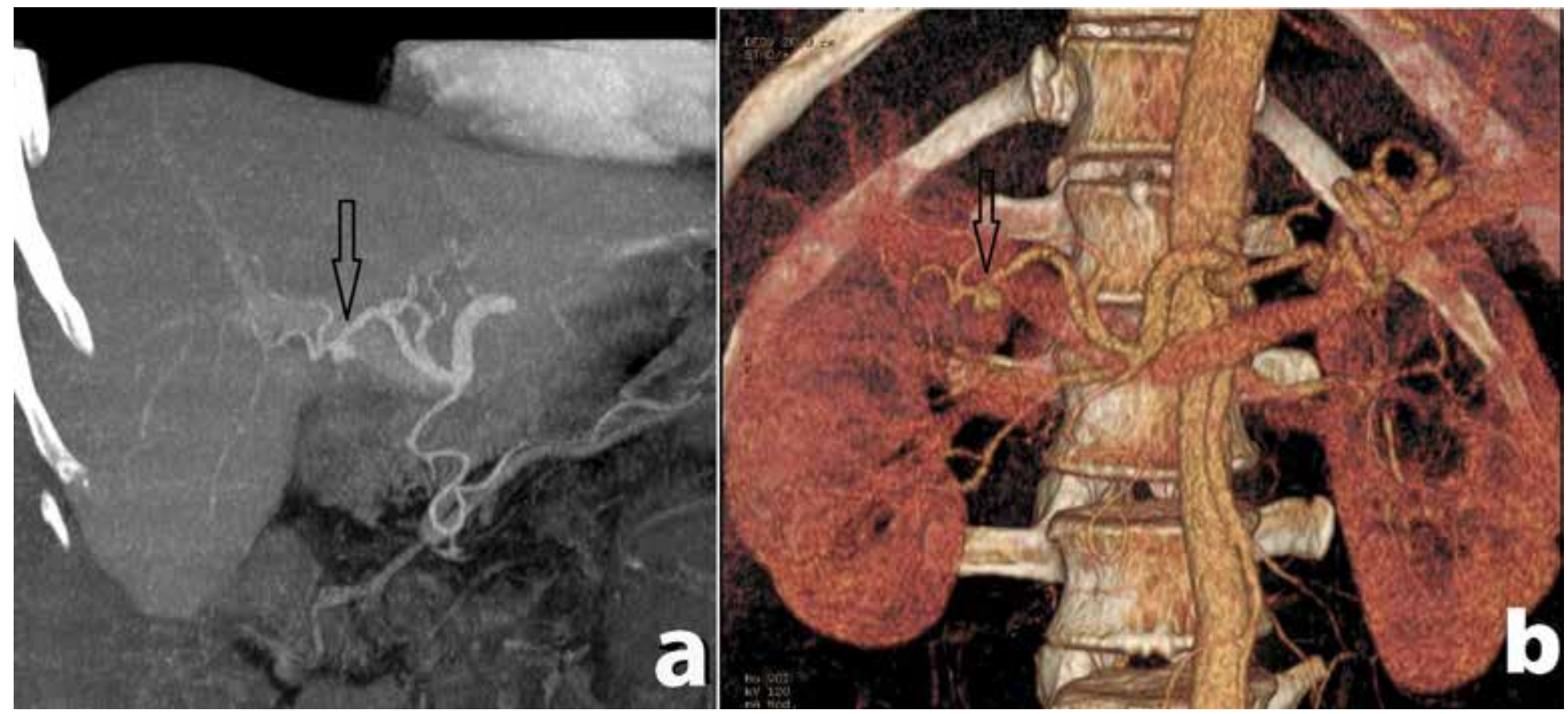

Figure 1.Contrast-enhanced computed tomography image showing pseudoaneurysm of the right hepatic artery (shown with arrow) in (a) coronal plane, and (b) 3-dimensional reconstruction.

$\mathrm{mg} / \mathrm{dL}$ and total bilirubin $0.8 \mathrm{mg} / \mathrm{dL}$. On the follow-up after 1,3 and 6 months, the patient was well.

\section{Discussion}

Hemobilia, in the past, was more common in traumatic patients accounting for $38.6 \%$ of all cases, followed by cholelithiasis $(15 \%)$, inflammation (13\%), vascular conditions $(10.7 \%)$ and oncologic issues $(6.2 \%) .{ }^{8}$ Today, however, the most common etiologic factor has become iatrogenesis. Twothirds of the cases in the series by Green et $\mathrm{al}^{6}$ were due to iatrogenic injuries. Pseudoaneurysms develop from damage to an arterial wall resulting in a rupture and formation of a sac walled by surrounding tissues and organs. ${ }^{9,10}$ The majority $(65 \%)$ of hepatic artery pseudoaneurysms occur after liver procedures while $35 \%$ occur after biliary procedures and only $5 \%$ occur after pancreatic procedures. ${ }^{11}$ The right hepatic artery is the commonest site among all hepatic artery pseudoaneurysms accounting for almost $80 \%{ }^{11}$ The presence of bile is known to damage blood vessels, so simultaneous injury to biliary structures can delay healing of an injured artery and predispose that artery to the formation of pseudoaneurysms. ${ }^{10-12}$

The clinical presentation of hemobilia is specified with two clinical syndromes: gastrointestinal bleeding and common bile duct obstruction. The triad of symptoms was described by Quincke, ${ }^{13}$ which is named after him, and includes biliary colic, jaundice and melena or hematemesis. Biliary colic and obstructive jaundice are both clinical manifestations of obstructive syndrome encountered in $70 \%$ and $60 \%$ of hemobilia cases, respectively; whereas melena and hematemesis, encountered in $90 \%$ and $60 \%$ of patients with hemobilia, respectively, are the clinical manifestations of gastrointestinal bleeding. ${ }^{13,14}$ Quincke's triad is encountered in only $13.5 \%$ to $22 \%$ of cases. ${ }^{6,15}$ Hemobilia usually involves minor bleeding and stops spontaneously in most cases, especially in cases when the etiology is cholelithiasis, inflammation or tumors. In the case of rapid bleeding, such as the cases due to vascular conditions, the blood flows rapidly into the duodenum, presenting as melena or hematemesis. In contrast, slow bleeding has the tendency to form clots and cause biliary obstruction because the blood does not mix with bile and forms separate layers due to the difference in gravity and surface tension. ${ }^{15,16}$ In our patient, Quincke's triad is present with melena as a manifestation of gastrointestinal bleeding.

Endoscopy can confirm the diagnosis of hemobilia in $10 \%$ of cases. ${ }^{17}$ However, endoscopy is mandatory in the evaluation of a patient presenting with symptoms of gastrointestinal hemorrhage and, in the case of hemobilia, its role is reduced to ruling out other possible causes of bleeding. ${ }^{18,19}$ Ultrasonography can be utilized in the initial evaluation of hemobilia. Sonographic features may include dilation of the common bile duct which was reported to be present in $28 \%$ of cases..$^{20}$ On the other side, the presence of fresh blood or clot within the biliary tree may yield an erroneous impression of duct size on ultrasonography. ${ }^{21}$ Computed tomography imaging is used in the evaluation of hemobilia increasingly more often which is also helpful in determining possible etiology, such as tumors, inflammation, and possible features, such as bile duct dilation and the presence of bile duct obstruction. ${ }^{22}$ In our patient also, computed tomography was successful to demonstrate the etiology of hemobilia. However, 


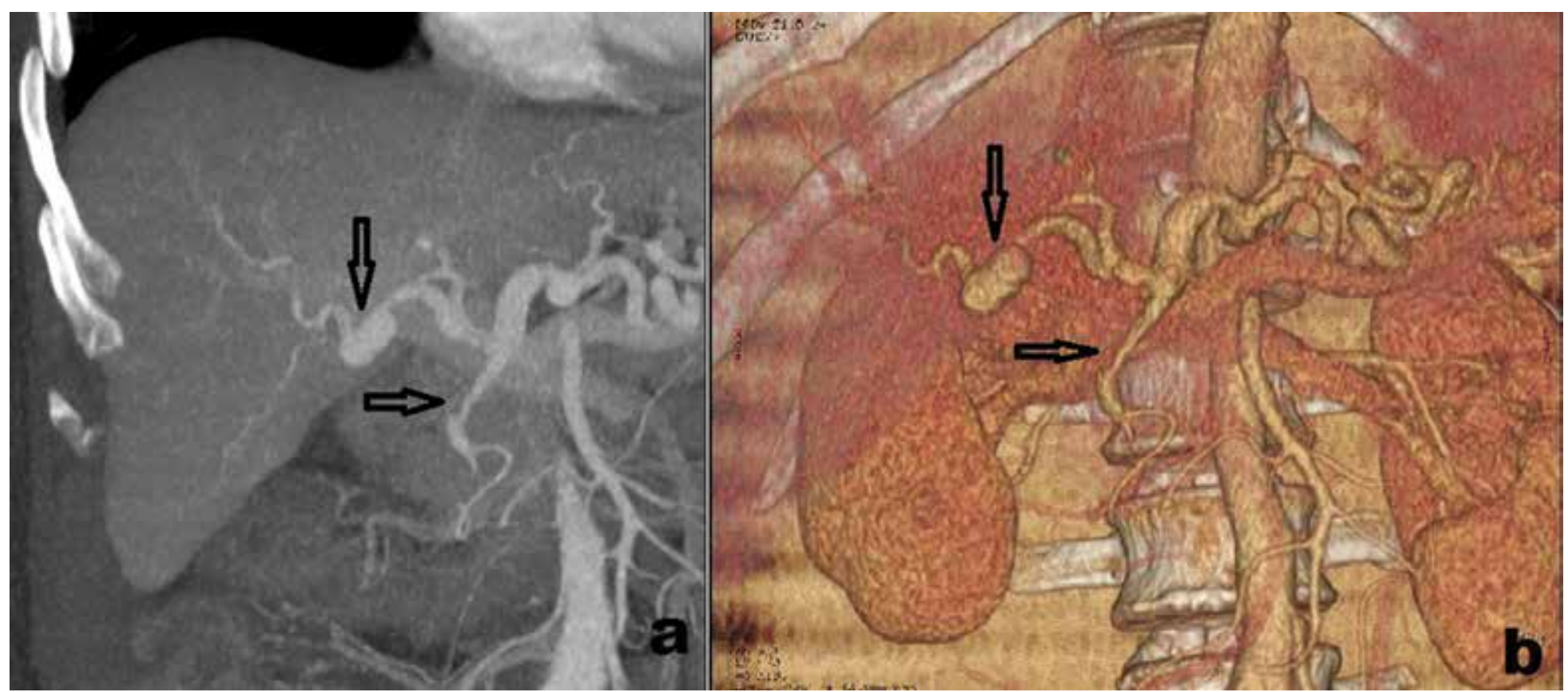

Figure 2.Contrast-enhanced computed tomography image showing recurrent pseudoaneurysm of the right hepatic artery (vertical arrow) and embolic obstruction of the gastroduodenal artery (horizontal arrow) in (a) coronal plane, and (b) 3-dimensional reconstruction.

MRI can be helpful in distinguishing a clot from a stone obstructing common bile duct. ${ }^{17}$ Angiography remains the most accurate modality of diagnosis with the sensitivity of $90 \%{ }^{6,23}$ Moreover, angiography can be directly transferred from diagnostic to therapeutic procedure, transarterial embolization, which is favored over surgery owing to its success rate over $80 \%$, good tolerance and minimal risks. ${ }^{23,24}$ Despite that high effectiveness of this procedure, $20 \%$ of cases can fail for different reasons. In our patient the reason seemed to be the incorrect choice of the embolizing agent. Polyvinyl alcohol particles are known to provide permanent occlusion by adherence to the vessel wall, causing stagnation of flow, in addition to lodging in the smallest vessel into which they will fit. ${ }^{25}$ However, the major disadvantages of polyvinyl alcohol particles are their tendency to aggregate, occluding vessels more proximally than might be expected based on stated size and the possible recanalization of the embolus. ${ }^{26,27}$ In our patients both disadvantages emerged as complications: the embolus recanalized and the gastroduodenal artery appeared to be embolized. In contrast, coils are permanent embolic agents that are typically used for occlusion of larger vessels and cause complete occlusion equivalent to surgical ligation. ${ }^{26,27}$

\section{Conclusion}

Transarterial embolization is a definitive treatment of hemobilia due to vascular issues. The correct choice of embolizing agent is half of the success of its management.

\section{References}

1. Philip S, Kamyab A, Jacobs M. Biliary cystadenocarcinoma: an unusual cause for recurrent hemobilia. Int Surg 2015;100(4):702-704.

2. Merrell SW, Schneider PD. Hemobilia--evolution of current diagnosis and treatment. West J Med 1991;155(6):621-625.

3. McGehee RN, Townsend CM, Thompson JC, Fish JC. Traumatic hemobilia. Ann Surg 1974;179(3):311-315.

4. Sandblom P. Hemorrhage into the biliary tract following trauma; traumatic hemobilia. Surgery 1948;24:571-586.

5. Wright PW, Orloff MJ. Traumatic hemobilia. Ann Surg 1964;160(1):42-53.

6. Green MH, Duell RM, Johnson CD, Jamieson NV. Haemobilia. Br J Surg 2001;88:773-786.

7. Chin MW, Enns R. Hemobilia. Curr Gastroenterol Rep 2010;12:121-129.

8. Sandblom P. Hemobilia (Biliary Tract Hemorrhage): History, Pathology, Diagnosis, and Treatment. Springfield, IL: Charles C Thomas; 1972.

9. Saad NE, Saad WE, Davies MG, Waldman DL, Fultz PJ, Rubens DJ. Pseudoaneurysms and the role of minimally invasive techniques in their management. Radiographics 2005;25 Suppl 1:S173-S189.

10. Vachhani PG, Copelan A, Remer EM, Kapoor B. Iatrogenic hepatopancreaticobiliary injuries: A review. Semin Intervent Radiol 2015;32(2):182-194.

11. Tessier DJ, Fowl RJ, Stone WM, McKusick MA, Abbas MA, Sarr MG, Nagorney DM, Cherry KJ, Gloviczki P. Iatrogenic hepatic artery pseudoaneurysms: an uncommon complication after hepatic, biliary, and pancreatic procedures. Ann Vasc Surg 2003;17(6):663-669.

12. Madanur M A, Battula N, Sethi H, Deshpande R, Heaton N, Rela M. Pseudoaneurysm following laparoscopic cholecystectomy. Hepatobiliary Pancreat Dis Int 2007;6(3):294-298.

13. Quincke H. Ein fall von aneurysma der leberarterie. Berl Klin Wochenschr 1871;30:349-352. 
14. Gachabayov M. CBD compression or Quincke's triad? J Min Access Surg 2016;12:90.

15. Kim KH, Kim TN. Etiology, clinical features, and endoscopic management of hemobilia: a retrospective analysis of 37 cases. Korean J Gastroenterol 2012;59:296-302.

16. Sandblom P, Mirkovitch V. Minor hemobilia. Clinical significance and pathophysiological background. Ann Surg 1979; 190: 254-264.

17. Senadhi V, Arora D, Arora M, Dutta S. Hemobilia caused by a ruptured hepatic cyst: a case report. J Med Case Reports 2011;5:26.

18. Yoshida J, Donahue PE, Nyhus LM. Hemobilia: review of recent experience with a worldwide problem. Am J Gastroenterol 1987;82:448-453.

19. Murugesan SD, Sathyanesan J, Lakshmanan A, Ramaswami S, Perumal S, Perumal SU, Ramasamy R, Palaniappan R. Massive hemobilia: a diagnostic and therapeutic challenge. World J Surg 2014;38:1755-1762.

20. Laing FC, Frates MC, Feldstein VA, Goldstein RB, Mondro S. Hemobilia: sonographic appearances in the gallbladder and biliary tree with emphasis on intracholecystic blood. J Ultrasound Med 1997;16(8):537-543.

21. Laffey PA, Brandon JC, Teplick SK, Haskin PH, Pavlides CA. Ultrasound of hemobilia: a clinical and experimental study. J Clin Ultrasound 1988;16(3):167-170.

22. Feng W, Yue D, ZaiMing L, ZhaoYu L, XiangXuan Z, Wei L, QiYong G. Iatrogenic hemobilia: imaging features and management with transcatheter arterial embolization in 30 patients. Diagn Interv Radiol 2016;22(4):371-377.

23. Srivastava DN, Sharma S, Pal S, Thulkar S, Seith A, Bandhu S, Pande GK, Sahni P. Transcatheter arterial embolization in the management of hemobilia. Abdom Imaging 2006;31:439448.

24. Vultaggio F, Morère $\mathrm{PH}$, Constantin $\mathrm{C}$, Christodoulou $\mathrm{M}$, Roulin D. Gastrointestinal bleeding and obstructive jaundice: Think of hepatic artery aneurysm. World J Gastrointest Surg 2016;8(6):467-471.

25. Quisling RG, Mickle JP, Ballinger WB, Carver CC, Kaplan B. Histopathologic analysis of intraarterial polyvinyl alcohol microemboli in rat cerebral cortex. AJNR Am J Neuroradiol 1984;5(1):101-104.

26. Vaidya S, Tozer KR, Chen J. An Overview of Embolic Agents. Semin Intervent Radiol 2008;25(3):204-215.

27. Lubarsky M, Ray CE, Funaki B. Embolization Agents-Which One Should Be Used When? Part 1: Large-Vessel

Embolization. Semin Intervent Radiol 2009;26(4):352-357.

\section{Author Affiliations}

Mahir Gachabayov, MD, PhD*; Kubach Kubachev, MD, PhD†; Sergey Mityushin, MD f, and Nonna Zarkua, MD, $\operatorname{PhD} \oint$

*Attending surgeon, Department of abdominal surgery, Vladimir City Clinical Hospital of Emergency Medicine, Vladimir/Russia.Email: gachabayovmahir@gmail.com †Professor, Department of surgery named after N.D. Monastyrskiy, North-Western State Medical University named after I.I. Mechnikov, Saint-Petersburg/Russia, Email: kubachev_kubach@mail.ru tChief surgeon, Department of surgery, Vladimir City Clinical Hospital of Emergency Medicine, Vladimir/Russia. Email:mityushin57@yandex.ru
$\S$ Assistant professor, Department of surgery named after N.D. Monastyrskiy, North-Western State Medical University named after I.I. Mechnikov, Saint-Petersburg/Russia. Email: tatazarkua@mail.ru 